\section{Case of Plasmodium knowlesi Malaria in Poland Linked to Travel in Southeast Asia}

\section{Szymon P. Nowak, Paweł Zmora, Łukasz Pielok, Łukasz Kuszel, Ryszard Kierzek, Jerzy Stefaniak, Małgorzata Paul}

Author affiliations: Poznań University of Medical Sciences, Poznań, Poland (S.P. Nowak, Ł. Pielok, Ł. Kuszel, J. Stefaniak, M. Paul); Institute of Bioorganic Chemistry, Polish Academy of Sciences, Poznań (P. Zmora, R. Kierzek)

DOI: https://doi.org/10.3201/eid2509.190445

We report a case of Plasmodium knowlesi malaria imported to central Europe from Southeast Asia. Laboratory suspicion of $P$. knowlesi infection was based on the presence of atypical developmental forms of the parasite in Giemsastained microscopic smears. We confirmed and documented the clinical diagnosis by molecular biology techniques.

$\mathrm{T}$ he simian malaria parasite, Plasmodium knowlesi, is an emergent public health threat for persons traveling to Southeast Asia (1). We report a case of $P$. knowlesi malaria imported to central Europe from Southeast Asia.

On June 25, 2018, a 27-year-old woman returned to Poland after an 8-month tourist stay in Southeast Asia (Appendix Figure 1, http://wwwnc.cdc.gov/EID/ article/25/9/19-0445-App1.pdf). The patient did not use malarial chemoprophylaxis during her travels. While in Sumatra, Indonesia, she experienced 2 episodes of subfebrile body temperature of $\leq 38^{\circ} \mathrm{C}$. After returning to Poland, she reported having general malaise, weakness, chills, and a low-grade fever. She consulted a family physician, who diagnosed pharyngitis and recommended empiric antimicrobial drug therapy, cephalosporin combined with a fluoroquinolone, which provided no clinical improvement. After another episode of fever (temperature $39^{\circ} \mathrm{C}$ ), she sought treatment at the regional hospital in Racibórz, Poland. Basic laboratory tests revealed leucopenia, thrombocytopenia, and elevated levels of C-reactive protein and procalcitonin. The patient did not have any chronic diseases or drug allergies. She was not pregnant, and her family history was unremarkable.

On July 5, 2018, the patient was transferred to the Department of Tropical and Parasitic Diseases, Poznań University of Medical Sciences, Poznań, Poland, because of high fever. At admission, on day 5 of her illness, she was conscious and responded logically. Her clinical status was stable. She was febrile (temperature $40^{\circ} \mathrm{C}$ ) and experiencing hypotension $(91 / 68 \mathrm{~mm} \mathrm{Hg})$, chills, headache, weakness, malaise, and tachycardia (110 bpm) but did not have signs of multiorgan failure. Laboratory analyses showed mild normocytic anemia (hemoglobin $10.3 \mathrm{~g} / \mathrm{dL}$, hematocrit $29.0 \%$, and erythrocyte count $3.34 \times 10^{12}$ cells/L); low levels of platelets $\left(22 \times 10^{9} / \mathrm{L}\right)$, leukocytes $\left(2.13 \times 10^{3} / \mu \mathrm{L}\right)$, neutrophils $\left(0.76 \times 10^{3} / \mu \mathrm{L}\right)$, and lymphocytes $\left(1.01 \times 10^{3} /\right.$ $\mu \mathrm{L})$; marked elevation of inflammatory markers C-reactive protein $(66.3 \mathrm{mg} / \mathrm{L})$ and procalcitonin $(0.67 \mathrm{ng} / \mathrm{mL})$; a high concentration of D-dimers $\left(6.48 \times 10^{3} \mathrm{mg} / \mathrm{mL}\right)$; slightly prolonged prothrombin time (12.9 s); and elevated lactate dehydrogenase level (249 U/L).

Staff examining the first thick and thin blood films during screening in the emergency department reported an "atypical mixed infection with $P$. vivax and $P$. $m a$ lariae with a strange morphology of the parasites" and a low parasitemia of $0.3 \%$. A reference microscopic analysis performed at the Department of Tropical and Parasitic Diseases, Poznań University of Medical Sciences, showed infected erythrocytes of normal size and shape with a lack of Schuffner stippling and Maurer's cleft. We observed multiple young trophozoites in the erythrocytes, with a delicate, thin ring of cytoplasm. Some also had narrow band shapes. In addition, we saw mature schizonts with $<16$ merozoites, large round gametocytes, and notable amounts of hemozoin pigment (Appendix Figure 2). ELISA revealed a high level of Plasmodium sp. IgM/ IgG $(52 \mathrm{U} / \mathrm{mL})$, but we could not identify the Plasmodium species from these features. We later used PCR to confirm $P$. knowlesi infection from peripheral blood collected in EDTA tubes and frozen at $-20^{\circ} \mathrm{C}$. In brief, we extracted DNA from a $1.2-\mathrm{mL}$ venous blood sample by using an automated nucleic acid extractor, MagCore HF16 Plus, with a MagCore genomic DNA large volume whole blood kit (RBC Bioscience Corp., https://www.rbcbioscience. com), according to standard protocol. To identify the Plasmodium species, we used nested PCR according to Komaki-Yasuda et al. (2). In patients with previously described $P$. falciparum malaria, we have observed a specific band for the parasite. We did not observe this band in the case-patient's sample, suggesting infection with another Plasmodium species. The $P$. vivax primers did not yield amplification, but the $P$. knowlesi oligos resulted in clear bands, indicating that this patient was infected with P. knowlesi (Figure). In addition, the P. knowlesi band diminished after malarial therapy, demonstrating treatment efficacy.

On the basis of the patient's travel history, clinical signs and symptoms, test results, and World Health Organization guidelines (3), we diagnosed uncomplicated $P$. knowlesi infection. The patient received oral artemether and lumefantrine combined with intravenous doxycycline and the parasites cleared in microscopic smears within 4 days. The patient's fever subsided, her blood morphology 


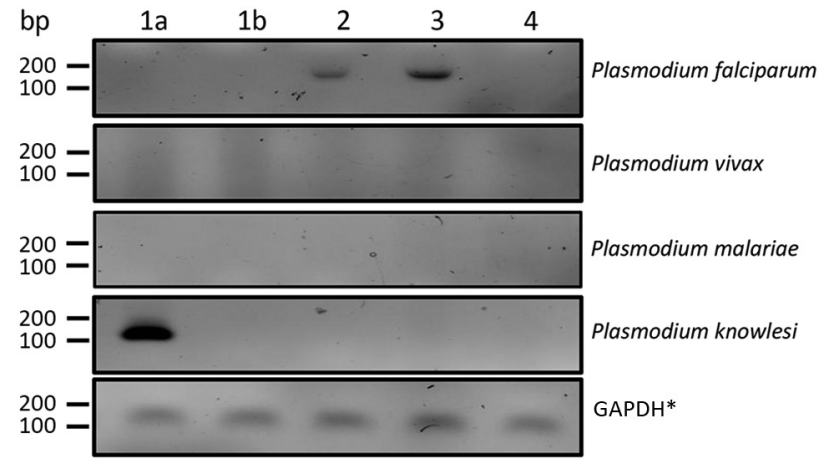

Figure. Nested PCR of Plasmodium knowlesi DNA isolated from a patient in Poland with recent travel to Southeast Asia. Lane 1a, patient sample from day of admission; lane $1 \mathrm{~b}$, patient sample taken 11 days after implementing malarial treatment; lanes 2 and 3, samples taken from patients previously diagnosed with Plasmodium falciparum malaria; lane 4, sample from an afebrile person from Poland with no history of travel to tropical countries. *GAPDH, glyceraldehyde 3-phosphate dehydrogenase.

and biochemistry parameters improved, and her levels of inflammatory and coagulation system markers decreased. In addition, PCR was negative for $P$. knowlesi DNA in peripheral blood after treatment. During a 3-month follow-up period, morphological and biochemical laboratory parameters all normalized, and the level of Plasmodium-specific antibodies diminished to $\leq 28 \mathrm{U} / \mathrm{mL}$.

In conclusion, we describe a rare case of $P$. knowlesi infection imported to Poland in a traveler returning from Southeast Asia. Previous research studies report imported cases of $P$. knowlesi malaria in travelers returning to other countries in western and northern Europe, including Spain, Italy, France, Germany, and Sweden (4-10). Travelers from Poland increasingly choose Southeast Asia as a common and popular destination. With that in mind, parasitology laboratories in Poland could diagnose P. knowlesi more often as an etiologic agent of tropical malaria. The ambiguous morphology and low number of parasites seen in microscopy make diagnosing $P$. knowlesi difficult. Proper diagnosis relies on thorough epidemiology, including travel history, augmented with molecular biology techniques.

\section{Acknowledgments}

The authors thank Matylda Kłudkowska and Krystyna Frąckowiak for technical assistance in microscopy.

\section{About the Author}

Dr. Nowak is a physician and research fellow at the Department and Clinic of Tropical and Parasitic Diseases, Poznań University of Medical Sciences, Poznan, Poland. His research interest is in imported tropical diseases.

\section{References}

1. Singh B, Kim Sung L, Matusop A, Radhakrishnan A, Shamsul SS, Cox-Singh J, et al. A large focus of naturally acquired Plasmodium knowlesi infections in human beings. Lancet. 2004;363:1017-24. https://doi.org/10.1016/S0140-6736(04)15836-4

2. Komaki-Yasuda K, Vincent JP, Nakatsu M, Kato Y, Ohmagari N, Kano S. A novel PCR-based system for the detection of four species of human malaria parasites and Plasmodium knowlesi. PLoS One. 2018;13:e0191886. https://doi.org/10.1371/ journal.pone. 0191886

3. World Health Organization. Guidelines for the treatment of malaria. 3rd ed. Geneva: The Organization; 2015.

4. Ta TT, Salas A, Ali-Tammam M, Martínez MC, Lanza M, Arroyo E, et al. First case of detection of Plasmodium knowlesi in Spain by real time PCR in a traveller from Southeast Asia. Malar J. 2010;9:219. https://doi.org/10.1186/1475-2875-9-219

5. De Canale E, Sgarabotto D, Marini G, Menegotto N, Masiero S, Akkouche W, et al. Plasmodium knowlesi malaria in a traveller returning from the Philippines to Italy, 2016. New Microbiol. 2017;40:291-4.6. Berry A, Iriart X, Wilhelm N, Valentin A, Cassaing S, Witkowski B, et al. Imported Plasmodium knowlesi malaria in a French tourist returning from Thailand. Am J Trop Med Hyg. 2011;84:535-8. https://doi.org/10.4269/ ajtmh.2011.10-0622

7. Froeschl G, Beissner M, Huber K, Bretzel G, Hoelscher M, Rothe C. Plasmodium knowlesi infection in a returning German traveler from Thailand: a case report on an emerging malaria pathogen in a popular low-risk travel destination. BMC Infect Dis 2018;18:148. PubMed https://doi.org/10.1186/s12879-018-3059-Z

8. Bronner U, Divis PC, Färnert A, Singh B. Swedish traveller with Plasmodium knowlesi malaria after visiting Malaysian Borneo. Malar J. 2009;8:15. https://doi.org/10.1186/1475-2875-8-15

9. Seilmaier M, Hartmann W, Beissner M, Fenzl T, Haller C, Guggemos W, et al. Severe Plasmodium knowlesi infection with multi-organ failure imported to Germany from Thailand/Myanmar. Malar J. 2014;13:422. https://doi.org/10.1186/1475-2875-13-422

10. Froeschl G, Nothdurft HD, von Sonnenburg F, Bretzel G, Polanetz R, Kroidl I, et al. Retrospective clinical case series study in 2017 identifies Plasmodium knowlesi as most frequent Plasmodium species in returning travellers from Thailand to Germany. Euro Surveill. 2018;23. https://doi.org/10.2807/ 1560-7917.ES.2018.23.29.1700619

Address for correspondence: Szymon P. Nowak, Poznań University of Medical Sciences, Department and Clinic of Tropical and Parasitic Diseases, 49 Przybyszewskiego St, 60-355 Poznań, Poland; email: snowak@ump.edu.pl 